\title{
DEBATIR O NO DEBATIR: HE AHÍ LA CUESTIÓN UNA REFLEXIÓN DE LA CAMPAÑA ELECTORAL EN COSTA RICA 2013-2014
}

\section{TO DEBATE OR NOT TO DEBATE: THAT IS THE QUESTION \\ A REFLECTION ON COSTA RICAN ELECTION CAMPAIGN, 2013-2014}

\author{
Pablo E. Carballo Chaves*
}

\begin{abstract}
RESUMEN
Las últimas elecciones en Costa Rica presentaron una dimensión inusual del contexto de desarrollo socio-político. Una de esas dimensiones fue el escenario de los debates transmitidos por diferentes medios de comunicación. El interés de este documento versa sobre un análisis sistemático de los elementos surgidos y usados en el desarrollo de varios debates puntuales en el periodo que comprende la campaña electoral. Por medio de una metodología puntual se hace una síntesis analítica de los marcadores usados por los candidatos a presidente y se busca precisar una dimensión del proceso electoral y sociopolítico costarricense.
\end{abstract}

PALABRAS CLAVE: COSTA RICA * ELECCIONES * DEBATE * MEDIOS DE COMUNICACIÓN

ABSTRACT

The recent elections in Costa Rica presented an unusual social-political dimention. One of those dimensions was the debates transmitted by different mass media. The main topic of this paper addresses a systematic analysis of symbolic elements encountered and used in several debates during the presidential electoral campaign. Through an specific methodology, we identified markers and different contents used by the candidates during their speeches, and analize the electoral process and make linkages with contextualizations.

KEYWORDS: COSTA RICA * ELECTIONS * DISCUSSIONS * MASS MEDIA

* Universidad de Costa Rica (UCR) y de la Universidad Estatal a Distancia (UNED).

Carballopablo@gmail.com 
EL DEBATE: DE LO “ACCESORIO" A LO "NECESARIO"

Lo que pareciera ser "obvio", ya no lo es tanto. Debatir o no debatir en una campaña electoral pareciera que se volvió o está volviendo en una opción a discreción para ciertas estrategias de campaña en Costa Rica. En la última contienda electoral costarricense (2013-2014) para presidente y para diputados, el debatir fue inicialmente un accesorio ya supuestamente rutinario (casi descartable del marketing electoral). En cierta lógica política cínica, un mal necesario, y su argumento como acto fundamental del ejercicio político representativo, un resabio de la política "premediática". Pero pareciera, según una reflexión de los resultados de las votaciones, que tal vez los debates tuvieron más peso de lo que se esperaba. No tanto por sí mismos, sino por una combinación de factores de contexto, escenario y candidatos, estos últimos puestos con una importante centralidad en este artículo. Sin obviar lo teatral de la presentación pública de los candidatos, la teatralización esta vez tuvo un desempeño ambivalente en el nivel del debate. No significa que la teatralización en el acto de debatir sea una novedad, sino que tuvo consecuencias no necesariamente esperables del espectador sobre los candidatos. Para unos el debatir se presentó como opción en varios aspirantes presidenciales (asistir o no), algunos otros por estrategia, lógica y ética política electoral, asistieron. Unos no se presentaron por crítica al sistema desigual de participación mediática en general (medios comerciales, universitarios, nacionales) o porque no eran invitados, por considerarlos "inofensivos o prescindibles" de los debates, por no tener "opciones reales" de ganar o no tener "muchos" votos.

El presente artículo establece, bajo el escenario brevemente descrito, un análisis a partir de preguntarse: ¿cuál fue el peso discursivo de los candidatos en los debates en el contexto de la campaña electoral costarricense 2013-2014? Desde esa pregunta se estableció un objetivo de estudio general que se basa en analizar el impacto y el desempeño discursivo de los candidatos en los debates mediáticos durante la campaña electoral. Aclarando en este cometido que el estudio toma como base los debates televisados, debido a que tienen un alcance masivo $y$ pueden ser considerados como de alto impacto en la sociedad. En este sentido, la metodología debe ser leída como en construcción y señalando que busca articular su reflexión sobre la justificación de una preponderancia mediática, mucho más explícita que en pasadas campañas electorales.

\section{BREVE CARACTERIZACIÓN METODOLÓGICA PARA EL ESTUDIO DEL DEBATE}

El debatir es un acto que es fundante en lo político y lo público, por tanto, forma parte de un tratamiento en donde convergen: las estructuras de partido, la versatilidad del candidato, la dinámica técnica del formato del debate $y$ por último pero no necesariamente menos importante (aunque podrían ser menoscabadas), las circunstancias temáticas estructurales o coyunturales del momento. De ahí que el interés de esta reflexión doble, sea el uso que se le dio a los debates desde dos entradas o abordajes: a) ¿cuál fue el manejo estratégico de los debates en términos de que los candidatos asistieran o no a ellos?; y b) ¿cómo usaron los candidatos, los debates en términos estratégico-discursivos? Ambos puntos convergen en la reflexión sobre el uso del debate (aunque se concentrará el análisis en el punto b). Para los puntos a $y$ b, se toman en cuenta elementos para poder valorar dicha asistencia $y$ uso estratégico (cuadro 1). El procedimiento consiste en estudiar dos dinámicas (ausencia y presencia-discursiva) que se dieron en relación a los debates y que marcan una mirada del comportamiento político. Es decir, una dimensión socio-política donde la y el ciudadano(a) elector(a) puede evaluar comparativa y conflictivamente las candidaturas, $y$ donde el factor mediático tiene todavía un filtro legitimador de la oficialidad política. 
CUADRO 1

ELEMENTOS PARA ANALIZAR EL USO DEL DEBATE 2014

\begin{tabular}{ll}
\hline \multicolumn{1}{c}{ PUNTO A. ASISTIR O NO } & \multicolumn{1}{c}{ PUNTO B. USO ESTRATÉGICO } \\
\hline $\begin{array}{l}\text { 1. Partido al que pertenece. Trayectoria histórica (nuevo/ } \\
\text { viejo). }\end{array}$ & 1. Programa e ideología de partido. \\
$\begin{array}{ll}\text { 2. Tendencia en intención de voto, según las encuestas } \\
\text { para la elección del } 2014^{*} .\end{array}$ & $\begin{array}{l}\text { 2. Versatilidad y creatividad del candidato (auto- } \\
\text { calificativos /trayectorias/uso de los temas estructurales y } \\
\text { coyunturales). }\end{array}$ \\
\hline
\end{tabular}

Fuente: $\quad$ Elaboración propia.

* Se toma en cuenta la tendencia de voto de las encuestas debido a que hay varios partidos que son recientes y no tienen trayectoria histórica, pero forman parte del espectro de candidatos.

Se debe tomar en cuenta el formato del debate, el cual pese a que puede ser establecido por una entidad externa a los partidos (un canal de televisión u otra fuente), pueden favorecer a uno frente a otro u otros tanto con cierto propósito o sin buscarlo adrede. En este sentido es fundamental tener presente que este artículo es un análisis de la dinámica del desempeño de los candidatos en los debates (los mayormente mediatizados), no de la composición técnica, en la que se muestra la combinación del uso estratégico de su presentación individual y su enfrentamiento con otros. La intención del cuadro 1 es indicar elementos por los cuales no se asiste a un debate o debates, así como el desempeño de los candidatos que asistieron en términos de discurso. Esto con el fin de poder sacar conclusiones analíticas del impacto en las elecciones.

Un factor a tener presente dentro de este acercamiento a la dinámica del debate es la lógica actual en los debates, desde el punto de vista del escenario de masas que los medios de comunicación proponen. Al referirse de que en un debate de cobertura nacional se está ante la coordinación de cuatro elementos del debate mediático: 1) los candidatos mismos; 2) la producción del evento (presentadores, camarógrafos, etc.); 3) audiencia en vivo; y 4) audiencia masiva -virtualizada- (los llamados televidentes o Internet-videntes). No obstante, lo central en este estudio es el desempeño creativo y armonización discursiva entre propuestas ideológicas, circunstancias coyunturales y donde los candidatos logran aprovechar márgenes de sentido para crear una persuasión sobre el espectador y futuro elector. En aras de aportar al estudio desde la comunicación política en Costa Rica, el estudio de los debates y lo que los candidatos y partidos hicieron mediante ellos, se posiciona en la necesidad de rescatar la construcción de argumentos y lucha simbólicodiscursiva (Punto b. Uso estratégico) que en esta campaña se hizo desde los márgenes de los mismos debates.

\section{RESULTADO DE LAS ELECCIONES Y CONTEXTO DE LA CAMPAÑA POLÍTICA}

El escenario electoral de febrero $y$ abril tuvo un comportamiento que se analiza en este documento desde la hipótesis de que los debates en el contexto de estas elecciones tuvieron un significativo aporte en la discusión y decisión, mucho más que en pasadas elecciones. No se indica que no lo hayan tenido en otras elecciones, lo que se señala es que en estas particulares elecciones, el peso de ver y tomar en cuenta los debates (unido a otros elementos socio-históricos de contexto estructurales y coyunturales) fue potenciado por su capacidad de exponer a los candidatos con mayor continuidad $y$ en una abierta frontalidad de enemistad, así como ver a los candidatos en la impronta de una confrontación y sobre-exposición. 
Principalmente, en la primera ronda, se podría derivar que el desempeño en los escenarios de los debates produjo un resultado "inesperado" en términos de lo que las encuestas de intención de voto habían indicado $y$ lo que las elecciones mostraron meses antes (cuadro 2). El cuadro 2 muestra los resultados de la primera ronda (2 de febrero) divididos en los 6 con mayor $y$ los 7 con menor cantidad de votos $y$ de la segunda ronda (6 de abril) según los dos primeros lugares de la primera ronda 2014.

CUADRO 2

PARTIDOS* SEGÚN EL RESULTADO DE LAS VOTACIONES PRESIDENCIALES
2014

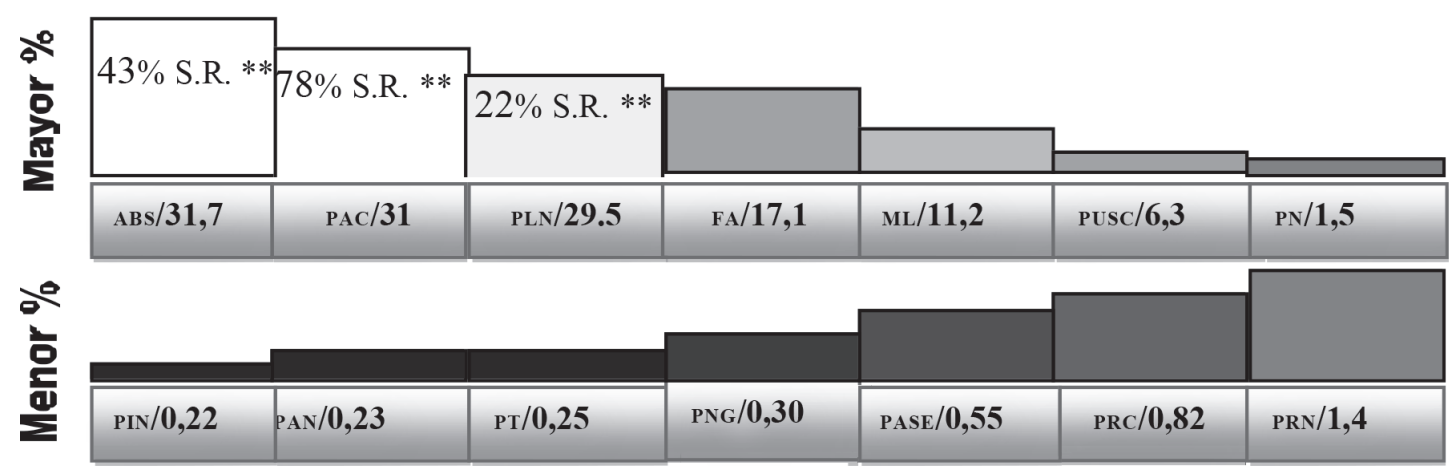

Fuente: Elaboración propia a partir de los datos del Tribunal Supremo de Elecciones. Costa Rica, 2014.

* ABS: Abstención. PAC: Partido Acción Ciudadana. PLn: Partido Liberación Nacional. FA: Partido Frente Amplio. ML: Partido Movimiento Libertario. Pusc: Partido Unidad Social Cristiana. PN: Partido Patria Nueva. PRN: Partido Restauración Nacional. PRC: Partido Renovación Costarricense. PASE: Partido Accesibilidad Sin Exclusión. PNG: Partido Nueva Generación. PT: Partido de los Trabajadores. PAN: Partido Avance Nacional PIN: Partido Integración Nacional. **: Segunda Ronda.

Estos resultados se valoran desde el desempeño que tuvieron los candidatos que quedaron en las primeras 6 posiciones en las elecciones. Se está ante la necesidad de considerar lo que ocurrió en dichos debates respecto al desempeño de los candidatos. Existe un espectro de análisis de muchos debates, de los cuales se escogieron para la reflexión, aquellos que fueron transmitidos a nivel nacional en diferentes canales de televisión, estatales (canal
13) y la televisión privada (canal 6 y 9-Repretel, canal 7-Televisora de Costa Rica). Asimismo, que hubo otros a los cuales no se tuvo acceso por no ser difundidos masivamente. El interés por producir estos debates de manera continua desde los mismos medios de comunicación, ayudó a crear un clima de interés, así como una posibilidad de mayor presencia de algunos candidatos, para quienes el acceso publicitario les era más difícil por criterios económicos. 
CUADRO 3
DEBATES Y ASISTENCIA, SEGÚN CANDIDATOS*

2013-2014

\begin{tabular}{|c|c|c|c|c|c|c|c|}
\hline CANDIDATOS & DEB. 1. & DEB. 2. & DEB. 3. & DEB. 4. & DEB. 5. & DEB. 6 . & DEB.7. \\
\hline \multirow[t]{2}{*}{ Sede/Fecha. } & $\mathrm{UNA}^{1}$ & $\mathrm{TSE}^{2}$ & Canal 9 & Canal 9 & Canal 7 & $\mathrm{UCR}^{3}$ & Canal 6 \\
\hline & $23 / 10 / 13$ & $5-6 / 01 / 14$ & $08 / 01 / 14$ & $12 / 01 / 14$ & $19 / 01 / 14$ & $21 / 01 / 14$ & $27 / 01 / 14$ \\
\hline PLN/Araya & & & & & & Cancelado & \\
\hline FA/Villalta & & & & & & Cancelado & \\
\hline ML/Guevara & & & & & & Cancelado & \\
\hline PAC/Solís & & & & & & Cancelado & \\
\hline Pusc/Piza & & & & & & Cancelado & \\
\hline PIN/Muñoz & & & & & & Cancelado & \\
\hline PASE/López & & & & & & Cancelado & \\
\hline PRC/Orozco & & & & & & Cancelado & \\
\hline PN/Corrales & & & & & & Cancelado & \\
\hline PAN/Echandi & & & & & & Cancelado & \\
\hline PRN/Avendaño & & & & & & Cancelado & \\
\hline PT/Monestel & & & & & & Cancelado & \\
\hline PNG/Mena & & & & & & Cancelado & \\
\hline
\end{tabular}

Fuente: Elaboración propia a partir de datos del TSE, prensa y televisión.

1. Universidad Nacional de Costa Rica.

2. Tribunal Supremo de Elecciones de Costa Rica. Ese debate se hizo en dos días por la cantidad de los participantes, por lo que se optó por seguir la misma lógica de ser un solo debate y no dividirlo. Transmitido por Canal 13 (SINART: Sistema Nacional de Radio y Televisión) del Estado.

3. Universidad de Costa Rica. En este debate (pensado en dos partes también) se dio una ausencia/abstención masiva de candidatos de participar, por lo cual la dinámica pasó de ser de un debate a un "conversatorio", y el debate como tal se canceló. Véase: Cambronero, 2014. Se tomó la decisión de recordar la programación de dicho debate aunque se haya cancelado, porque esto ayuda a evidenciar el punto de desaceleración de la capacidad de generación y/o desaceleración de los debates.

* Se debe recordar que en varios debates no se invitó a la totalidad de los candidatos. Sino que se invitó a los 5 que son los partidos más viejos, como también los que iban encabezando las encuestas de intención de voto para diferentes momentos. Además, todos los debates están dentro del margen oficial de la campaña que empezó oficialmente el 2 de octubre de 2013.

El cuadro anterior permite visualizar tres elementos que orientan la investigación. Los candidatos que quedaron en los primeros puestos son los que coinciden con los más difundidos en televisión. En algunos casos también coincide con los partidos más antiguos, como es el caso del Partido Liberación Nacional, pero en otros, no tanto, como los partidos que surgieron en el siglo XxI, Partido Acción Ciudadana y el Partido Frente Amplio. Esto deja un margen analítico para interpretar la nueva composición socio-partidista en el contexto general en que se produjeron los distintos debates. Esto tiene de fondo un crecimiento de una posible nueva construcción bipartidista o una posible pluralidad de partidos, que todavía hoy del todo no está clara. Sin embargo, es importante rescatar la mutación o la idea de híbridos que a nivel político se ha venido gestando, siendo un ejemplo importante el que durante 
los años 1998-2006, se generó en relación a los nuevos partidos: "el PLN llevaba ya dos elecciones perdidas y el PAC lo había golpeado cuando surgió de sus propias entrañas en el año 2000, acusándolo de corrupción. En el debilitamiento del PUSC, otros factores adicionales incidieron: ocho años en el poder y una administración con poco prestigio" (Rodríguez, 2013). Además, durante la campaña del $\mathrm{TLC}^{1}$ con Estados Unidos, el PAC posicionó una simbología de patriotismo que tuvo una importancia clara en la densidad electoral posterior.

Además, sin profundizar en demasía, es fundamental abordar elementos de la situación particular de las campañas pasadas. Primero, es la segunda vez en la historia electoral en Costa Rica que ocurre una segunda ronda, la primera en el 2002 y en la recién acontecida, lo cual es un margen pequeño para valorar el comportamiento socio-electoral en dichas eventualidades. En segundo lugar, el candidato Johnny Araya del partido más fuerte, históricamente desde 1951 -Liberación Nacional-, en el impase entre la primera y segunda ronda realizó un comunicado de que no seguirá en el desempeño activo de la campaña ${ }^{2}$. Esto dejó en un ambiguo contorno social a la población votante.

Además, el hecho de que Luis G. Solís ganara las elecciones en ambas rondas puede dividirse analíticamente, sin embargo, se concentrará en el estudio de los debates que tiene un principal peso en los momentos previos a la primera ronda, pero que a su vez habría que analizarla en investigaciones posteriores,

$1 \quad$ El debate y la lucha social en relación con el TLC, fueron dinámicas políticas que han marcado la primera década del siglo xxI (Rojas, 2009; Rovira, 2007; Govaere y Ocampo, 2005 y Flórez-Estrada y Hernández, 2004) y desde esta perspectiva han suscitado una especie de recurrir al debate como mecanismo de importancia para una solidificación del arte político.

2 Johnny Araya no renunció a su candidatura, lo cual no es permitido a nivel constitucional: Constitución Política de Costa Rica, art. 138. Lo que realizó es un comunicado público el día 5 de marzo del 2014 avisando sobre "su" decisión de no seguir en campaña activa en vistas de la próxima segunda ronda. Para ver dicho comunicado: https://www.youtube.com/watch?v=SHPbfQ7KzxU donde fue consecuencia de lo acontecido en el transcurso de la segunda ronda electoral realizada el 6 de abril.

\section{EL ESCENARIO COMO OBSTÁCULO PARA LA POLÍTICA}

La reflexión sobre el desempeño político $y$ lo verbal van de la mano desde hace milenios. En cierto sentido no desproporcionado, es en el acto verbal donde buena parte de la exposición política de las ideas se lleva a cabo y se distribuye en el ideario social. Sin embargo, existen espacios diferenciados en la política que tiene ese sentido verbal ampliamente refinado $y$ que tiene mayor resonancia, en donde se presentan fines y objetivos psicológicos $y$ argumentativos (logos) específicos y más consistentes. El debate, sea antiguo, clásico, moderno, etc., es uno, si no el más importante espacio para llevar a cabo ese arte verbal -la retórica ${ }^{3}$ - en su sentido político más acabado 4 . Es ahí donde se inicia y muchas veces se canaliza a:

3 El término retórica tiene dos enfoques epistémicos contrapuestos. La versión platónico/aristotélica, frente a la versión sofista (que también ha sido exhibida desde la misma línea platónica). La versión de la línea platónica y aristotélica ubica a la retórica como un arte principalmente persuasivo, donde inclusive el logos está a disposición del objetivo de persuasión. Esto se debe a que "Platón subordina la política a los presupuestos y finalidades de la ética" (Guadalupe, 1982: 49). Mientras que la retórica desde la línea sofista, bajo ciertas miradas analíticas es un acto ético también, pero que debe ajustarse a una dimensión persuasiva, pero aún así es una versión simplificada (por el mismo Platón) y no deja ver la posible teoría del lenguaje y la visión epistémica y condiciones del conocimiento de fondo (Véase: Troncoso, 1983: 91). Los principales exponentes de la Grecia clásica son Protágoras y Gorgias. En este documento, la visión sobre la retórica se concentra en la versión de una reflexión retórica de construcción y racionalidad, en donde la persuasión es un componente, pero no el componente determinante de la versión platónica.

4 No se está diciendo que en el debate no haya estratagemas, ni persuasión, ni amagos e intentos de engaño o mentira. Sino que en el debate, existe la posibilidad, más que en cualquier otro escenario de que pueda aparecer o se motive a que aparezca el logos, es decir, la versión crítica tanto del que habla al público (un candidato) como una criticidad desde el que interpreta. 
... la retórica (el arte de la persuasión verbal) como una suerte de "ciencia política". En la polis griega y en el imperio romano, la tradición retórica formaba parte del entrenamiento de oradores que cumplían importantes funciones públicas, incluso funciones políticas, $y$, en cierto modo, proporcionaba un aparato para la observación crítica del comportamiento verbal político (Chilton y Schäffner, 2000: 297).

El debate sería ese aparato de observación crítica del comportamiento verbal político, por utilizar la terminología de Chilton y Schäffner; es decir, es primordialmente en los debates $y$ no en el resto de manifestaciones de la campaña política (anuncios de diversa naturaleza), en que se puede aproximar a una evaluación con mayor contenido crítico (el logos) desde un punto de vista general, sobre aquellas personas que optan o son candidatos o candidatas a cargos públicos.

La idea no versa sobre señalar que los debates son ajenos a caer en un ethos y pathos aristotélicos. Los debates son también propensos a la auto-referencialidad de los candidatos (ethos) o a usar las pasiones de la audiencia o espectadores (pathos). Pero desde una perspectiva analítica es por medio y a través de los debates donde se puede o podría rescatar, mucho más que en otros espacios, el uso del logos -de los elementos dialéctico/discursivos ${ }^{5}$ - (Aristóteles, 2013). Es importante señalar que no se indica tampoco que en los anuncios u otras difusiones de las campañas de los partidos, carezcan del todo de argumentos y razones. Pero en esos productos, el nivel de control

$5 \quad$ Es importante señalar que en el Arte de la retórica de Aristóteles, lo discursivo y lo dialéctico van asociados con el carácter racional (la aplicación del carácter deductivo e inductivo) de la construcción de los mensajes, por lo cual se hace una continuidad en la terminología y se optó por utilizar la capacidad discursiva también en ese sentido de hacer razonable el mensaje. Esto no inhibe a la situación de falsedad o de falsificación que puede contener un mensaje o una exposición específica. Unido con la idea de organización política fundamental en la vida del ser social-politicón humano (Aristóteles, 2004). sobre los elementos productivos es mayor que en los debates, por la participación de varios contendientes con intereses contrapuestos unos a los otros, es decir, en los anuncios, vallas, etc., la capacidad para un logos espontáneo y creativo, está muy disminuido en relación con un logos casi excluido por la dupla pathosethos que inclusive son sobredimensionados. De ahí que sea en el mismo debate que se exija al candidato varias cosas: 1 ) independencia $y$ relativa autosuficiencia de su equipo de campaña; 2) inteligencia relativa y visualización de soluciones ${ }^{6}$-soluciones tanto de problemas de agenda, como problemas para el candidato durante el debate-; 3) La sumatoria de capacidades de convencimiento y credibilidad. Estos puntos se buscan canalizar en el cuadro 1 indicado en la metodología, donde el uso estratégico que hacen los candidatos, en relación con su programa o marco ideológico, es clave para manifestar su logos, el cual a su vez puede ser asimilado o desacreditado.

El debate pudo haber sido, bajo una solidificación de su papel, una eventual fuerza que fue en contra de la versión de la política de mera persuasión y rutina electoral, y se convirtió en un significativo filtro para valorar al candidato, como se esperaría. La manifestación de un uso más depurado de las palabras, de una elucubración simbólica/oral mucho más convincente, estuvo muy ligado al acto de cuestionar y aumentar el uso del "pensamiento", aún sin disminuir la emoción, ya que según reflexiones teóricas pueden verse separadas: "el uso simbólico de las palabras sirve para la comunicación del pensamiento, mientras que el uso emocional consiste en la evocación, expresión o excitación de sentimientos y actitudes" (Dorfles, 1984: 167-168). Desde Dorfles se perfila que los debates fueron usados para ambas exposiciones, simbólicas y emotivas; pero que si bien se podría decir que da por descontado la emotividad que involucra, fue más bien el factor asociativo de lo simbólico/pensamiento/criticidad, el que pesó

6 Se indica de soluciones y no de problemas, ya que es más fácil crear problemas para los que ya se tienen soluciones. O tomar los problemas que son política o socialmente parte de las discusiones mediáticas. 
fuertemente dentro de un escenario político costarricense con un marcado descontento $y$ conflictividad creciente.

El uso simbólico es básico, sea en debate o cualquier otro medio, sea racional o no. La indagación gira bajo el particular de darle a la exposición simbólica el reconocimiento de haber re-introducido un logos en su condición dialéctica en estas elecciones; en las cuales la decapitación de lo medular de un debate -el criticismo y lo dialéctico- no se erradicó ( $y$ tuvo un peso clave). El debate es un dispositivo de control, pero que puede funcionar en doble vía: que a su vez puede ser controlado para beneficio de unos, o que por otro lado puede ayudar a controlar un efervescente ethismo o pathismo, por medio de una promoción explícita de una dialéctica/logos ${ }^{7}$.

Cabe referirse a que el logos no es una posición tampoco neutral. Es una dimensión socio-ideológica que alberga trayectorias de poder $y$ violencia $^{8}$, de desequilibrio $y$ de desigualdad en su uso y consecuencias. El logos, que en la contemporaneidad se asimilaría como la razón ${ }^{9}$, viene a ser el prisma ideológico de la modernidad. Bajo esta crítica totalmente válida, de pensar una neutralidad de la razón como técnica de la objetividad, no es la intención del documento ni resolverla, ni ocultarla. Pero si es necesario recalcar que tanto la razón, como los debates en el contexto de la democracia liberal representativa, ambos son elementos constituyentes del

$7 \quad$ Se reconoce en esta aseveración una ingenuidad, si se delega en un cuerpo aparentemente neutral de técnicos despolitizados, el desarrollo y planificación de los debates. La idea es que cada participante en el debate reconozca el potencial de cuestionar que se tiene y que en el caso costarricense del 2013-2014 fue manifiesto cuando canalizó elementos estructurales y coyunturales desde candidatos, principalmente con discursos que se calificaban de alternativos y teñidos con apelativos de cambio.

8 Sobre la razón y violencia en la modernidad véase: Foucault, 1976.

9 La razón ha sido el núcleo duro del desarrollo de la modernidad en Occidente, dos nombres que se asocian con este proceso fueron René Descartes como el iniciador de esta línea y también Inmanuel Kant, como el consolidador de la razón como pilar de las capacidades epistemológicas de los seres humanos. escenario político de fondo y que ambos están fuertemente relacionados desde el punto de vista de las posibilidades de legitimación sociopolíticas de la modernidad; de ahí, el porqué se busque analizarlas en conjunto.

Pese a las críticas que también se derivan de los conceptos y las críticas epistemológicas, lo que se busca es también la capacidad crítica y epistémica que albergan dichas concepciones, en este sentido "Logos, es una palabra griega que significa 'razón', 'lógica', 'lenguaje', 'ley'. El logos hace reinar una especie de equilibrio; procura que en la guerra entre los contrarios ninguno prevalezca de manera definitiva, pues, en ese caso, todo dejaría de existir" (Hersch, 2010: 15). De esta manera se recupera el concepto de logos como una calidad de fomento de equilibrio, tanto entre los antagonistas, así como con criterios de verosimilitud de los argumentos ${ }^{10} y$ principalmente, en la posibilidad de ser evaluados, criticados, así como defenderse de dichos argumentos.

\section{ACELERACIÓN E ILUSIONES}

La mediatización de la vida social ha reconstruido la forma en que se acerca a los colectivos y a los procesos sociales. La política como dinámica social con un permanente referente al poder, tanto socio-estructural como formalizado en las esferas burocráticas institucionales, se ha revestido de dicha mediatización, donde los discursos se han regenerado con una sobreutilización del recurso de la imagen, mediada a su vez por una avasalladora

10 Se distingue el uso de razón/logos en este texto de otros, como lo serían el de Rodríguez (2013), ya que en ese trabajo, la racionalidad es valorada como elemento discursivo por sí mismo, como elemento legitimante del discurso. Pero en cambio, la valoración aquí de razón es el resultado que tiene en la producción crítica que surge de los debates; es decir, no es valorar solamente si tal o cual candidato es racional o aparenta ser racional, sino más bien, es que en la dinámica del debate, por su sentido de estimular la creación y la argumentación con la mayor coherencia posible (aun a sabiendas de la posibilidad de mentir y persuadir), el oyente en su triple condición -ciudadano-público, audiencia- a su vez participa de una dilucidación y reflexión (sea mayor o menor) respecto a lo dicho. 
mecanización de la construcción de mundo o mundos pedidos a la carta. Esta sobreutilización ha estado acompañada por un aceleramiento en la agilidad comunicativa que la tecnología informática desde mediados del siglo xix ha venido generando. En este sentido:

Exactamente eso es lo que estamos viviendo en nuestras sociedades actuales, que se empeñan en acelerar todos los cuerpos, todos los mensajes, todos los procesos en todos los sentidos y que, con los medios de comunicación de masas modernas, han creado para cada acontecimiento, para cada relato, para cada imagen, una simulación de trayectoria hasta el infinito (Baudrillard, 2004: 10).

El escenario político mundial y en este caso de análisis, el costarricense, se nutre en esa línea de aceleración de los mensajes. Acelerar un mensaje no necesariamente involucra profundidad o reflexión, de hecho podría hasta ser contraproducente para una capacidad reflexiva. En este sentido, la lógica es bombardear con mensajes rápidos, puntuales $y$ a la larga, reiterativos, si se aplica la idea de aceleración a la situación electoral. Así se hace fundamental ideas des-contextualizadas, no necesariamente profundas, más sí políticamente correctas para generar una empatía de identificación partidaria o personal.

La "realidad social" es presionada, acelerada, re-evaluada en momentos de intereses políticos coyunturales o estructurales como serían las campañas electorales, haciendo y generando una representación nacional o regional convulsa.

La representación (también política) es en la actualidad una zona depresionaria, meteorológicamente depresionaria, que los medios de comunicación llenan con sus turbulencias, con las mismas consecuencias que la despresurización repentina de cualquier espacio. La más alta presión de la información corresponde a la más baja presión del acontecimiento y de lo real (Baudrillard, 2004: 90).
Se presiona con tanta "información" que vuelve conflictivo o caótico el encontrar sentido o sentidos a lo que ocurre, volviendo a los sentidos básicos y superficiales los más atractivos o los más fáciles a los cuales acceder $y$ atrincherarse de las turbulencias que dice Jean Baudrillard.

En el caso costarricense, uno de esos puntos de estabilidad anti-turbulencias sería el sentido del "centro", tan reclamado por todos $y$ todas en momentos de realidades propuestas como "extremas" o "extremistas". El remarcado de centro entra a su vez en la construcción ideológica costarricense que se conjuga con los adjetivos de: centro-iguales-pacíficos. Elementos que han convertido al entorno político electoral costarricense en un espacio discursivo plano, pero que en las últimas elecciones se ha re-actualizado involucrando elementos de "extremismos" (o aparentes extremismos) como opciones posibles y que han sido manipuladas desde distintas esquinas políticas.

En otras palabras, la lógica electoral costarricense tiene como núcleo duro una ilusión de neutralidad, que posiciona extremos y/o diferencias (aquel o aquellos que se posicionan como diferentes) como anomalías sociales. Pero la neutralidad esconde la conflictividad social, que aunque está presente se ha buscado disimular (principalmente por la misma posición del aparente centro) bajo un principio de convivencia. Es precisamente la conflictividad social uno de los puntos que un extremo (de hecho el extremo históricamente vilipendiado: la izquierda) parte de los temas de discusión, superando lo que habitualmente dentro del marketing político se ha buscado, que es la banalización o superficialidad de lo profundo:

El marketing se sirve de la palabra, la imagen y el sonido, que ponen al servicio de lo más profundo, que es lo más superficial: la estética, la personalización, el carisma, la banalidad de los mensajes políticos, y el cambio de la complejidad por la valla, el poster y el slogan que optimice y recoja en un enunciado feliz la quintaesencia de la oferta política que se pone en el mercado (Del Rey Morató, 1989: 81). 
La publicidad como base técnica de la política (en este caso la política electoral) convierte a cualquier recurso de una campaña en un posible enlatado de mensaje, incluyendo a los debates. Sin embargo, pese a esto el debate conserva una dimensión de polémica (lo cual es su fuerza) mucho más explícito que el resto de elementos publicitarios: vallas, posters, slogans, entre otros.

Los debates podrían ser vistos como desaceleradores del proceso, en el que la mediatización ha generado una vertiginosa turbulencia comunicacional; es decir, diferenciándose de enlatados (vallas, posters y pasa-calles), los debates son momentos en donde se hace énfasis en los acontecimientos más en cámara lenta, en una especie del ahora, donde se usa el logos por medio de la contextualización y la desvinculación partidista o ideológica, aunque posiblemente encubando otras.

\section{ARREPENTIMIENTO DE DERECHA Y "REIVINDICACIÓN" DE IZQUIERDA}

El entorno simbólico de los últimos 10 años se ha re-posicionado con matices de presión político-económica (como la disputa alrededor del TLC, así como por una continuidad de gobierno costarricense, el cual ha sido fuertemente criticado de manera reiterada). Así, antes, ser de izquierda era un símbolo de "maldad", pese a que se usó con esa connotación, ahora relucía como moda o como posición ética. Pareciera que se invertía lo que Jean Baudrillard (2004) recordaba como un arrepentimiento por ser de izquierda en tono euro-asiático; además se posiciona analíticamente que se podría hablar también de un arrepentimiento de ser liberacionista (pLN). Este fue un elemento que se manejó no tan explícitamente, aunque la idea estaba más presente de lo que el mismo PLN, en sus líderes de campaña pudieron intuir, aunque la insinuación se intentó repeler por el mismo candidato de Liberación Nacional bajo las prerrogativa del "cambió" y "la unión". La aceleración también funcionó en un sentido no solo de distorsionar social, sino también para recargar negativamente la insatisfacción hacia una facción histórica. Los debates son medios ideales para ubicar culpables, ya que las personas funcionan como chivos expiatorios, no solo de errores propios humanos, sino también de procesos sociales y políticos. En otras palabras, la aceleración es contraproducente dependiendo del momento en que se acelera $y$ de los espacios sociales en los que se muestra. En un debate, un proceso de aceleración choca contra un momento de desaceleración $y$ es en ese instante en donde se puede tener el tiempo de apuntar contra alguien, el blanco no está en movimiento o al menos está en un lugar ubicable, el problema o los problemas adquieren caras, las cuales son más fáciles de transar que dinámicas políticas o complejas interacciones sociales.

A su vez se da un mecanismo para lograr disminuir estos momentos de des-aceleración, haciendo desvanecer los énfasis en la tensión y la conflictividad de lo que acontece: "una manera de reducir la tensión es eliminar al público de la escena, excepto en la forma" (Chomsky, 2009: 365-366). Así, la televisión permite disminuir la vinculación candidato-público, pero sacrificando al ciudadano. Este mecanismo de control desde un poder central -mediáticamente hablando-permite mantener una hermética en el debate, concentrado en los mismos candidatos. De esta manera, los debates podrían presentarse como espacios de inter-ataques de los candidatos que siguen la lógica de representatividad de la democracia liberal, en la que el público seguiría sin ser participante en los asuntos públicos, sino un espectador.

La idea de des-acelerar es fundamental porque permite pensar en lo problemático, que resulta en la idea de la participación y relación con el público-elector. El proceso de indagación $y$ cuestionamiento del debate, lo "falso" y lo "verdadero" están en constante incertidumbre, lo que abre una veta al carácter crítico del público. La idea de lo falso, de alguien falso puede ayudar a valorar que tan creíble es alguien o alguna idea. En este sentido, el mismo Aristóteles aportó la skiagraphia, con la que hace alusión directamente con el engaño; es decir, no es la posibilidad de error fortuito, sino la idea misma de crear algo falso. Inclusive, la misma persona/ candidato puede producir sobre sí mismo una falsedad adrede. Pero a su vez, dentro de esa idea de construir falsedades, está la posibilidad 
de defenderse de dichas falsedades $y$ en este sentido: "por eso Aristóteles, igualmente atento a comprender lo que es como a darle normas, escribió su Política, sus Éticas, pero también una Retórica, destinada a establecer las reglas del juego" (Labarriere, 2001: 12). Dicha retórica es el plano de lineamientos, pero que no siempre son explícitos en el contexto y en la acción. Así continua Jean-Louis Labarriere señalando que:

...la retórica se dirige a esos usuarios de la cosa común que son los ciudadanos para los cuales 'si es vergonzoso no poder defenderse con su cuerpo, sería absurdo no tener vergüenza de no poder hacerlo mediante la palabra, cuyo uso es más propio del hombre que el uso del cuerpo' (I, 1, 1355 a 38-b2). El 'iay de los ciegos!' se transforma en el 'Ay de los sordos y de los mudos!', porque defenderse mediante la palabra es tanto saber hablar como saber escuchar, lo cual explica que todo discurso sólo puede comprenderse en función del destinatario que lo juzga (2001: 12).

La capacidad retórica no está solo en un emisor privilegiado, sino de la capacidad de reacción desde una retórica del público. Los debates serían mecanismos de mucha valía en la posibilidad de recrear una retórica defensiva o inclusive, contra ofensiva sobre las ideas de candidatos o partidos que se han apropiado o buscan apropiarse de símbolos de poder y ejecutar aspectos de violencia simbólica para mantener una preponderancia socio-política. El arrepentimiento, aunque silencioso, es un mecanismo retórico del público que es fundamental entender dentro del contexto simbólico que se experimentó de fondo en la campaña. El elemento del miedo señalado ampliamente en la campaña, fue arremetido desde esa capacidad retórica desde el público, realizando una relativa afrenta ante la oficialidad del poder, y sus construcciones del miedo. Evidenciando a su vez que:

...la producción de "temor oficial", es la clave de la efectividad del poder. El temor cósmico puede no precisar mediadores humanos; el temor oficial, como todos los demás artificios, no puede prescindir de ellos. El temor oficial sólo puede ser ingeniado artificialmente (Bauman, 2005: 69. Cursivas del autor ${ }^{11}$.

Así como el temor surge en lo oficial artificialmente, también artificialmente se pueden construir mecanismos de defensa desde diferentes frentes. Inclusive, en la defensa también se reposiciona un cuerpo ambiguo de izquierda, que recupera no sin complicaciones una legitimidad ${ }^{12}$. No tanto por su o sus ideologías, sino por ser una re-novedad en la crítica a un sistema en deslegitimación.

Este resurgimiento de "una izquierda" contribuye a revertir lo que sobre la misma izquierda y el comunismo se había señalado como línea de gobiernos liberales:

En general, 'es mejor tener un régimen fuerte en el poder que un gobierno liberal, si este es indulgente y laxo y está influido por los comunistas'. El término 'comunista' se utiliza en el discurso de los Estados Unidos en un sentido técnico, aludiendo a los líderes del movimiento obrero, organizadores campesinos, sacerdotes que organizan grupos de ayuda mutua, $y$ otros con las prioridades erróneas (Chomsky, 2009: 77).

Este sentido técnico descalificaba a cualquiera por ser de cierto estrato social o por su condición de espacio socio-laboral, no importando si efectivamente era comunista o no. Esta lógica, sin romperse necesariamente,

$11 \quad$ El concepto de "temor cósmico" lo recupera Zygmunt Bauman (2005) de la lectura de Mijail Bajtin, la cultura popular en la edad Media y en el Renacimiento: el contexto de Francois Rabelis (1965), en la cual dicha idea se centra en rescatar lo inconmensurable en términos de grande y fuerte, que da sentido de miedo, al ser claramente pequeños ante la idea de ese cosmos que abrumadoramente nos sobrepasa.

12 Para valorar un contexto fatídico para la izquierda y el comunismo costarricense en los socio-político (condicionando procesos electorales) véase: Molina y Lehoucq, 1999. 
resurge en el contexto costarricense desde una reivindicación de ataques simbólicos de líderes sociales (aunque no necesariamente sindicales, como en otros contextos). La participación de la juventud catapultó también un empuje en la crítica del discurso hegemónico donde los partidos tradicionales en sus miembros $y$ también desde las nuevas generaciones sufren el "arrepentimiento"13 antes mencionado. La reflexión sobre la izquierda es efímera, no tiene aquí una profundidad sistemática, sino que se toma como parte del contexto en el cual se enunciaron los discursos ${ }^{14} y$ las ideas de los candidatos, lo cual es fundamental entenderlo en el contexto de campaña que no es el mismo necesariamente que el contexto de un gobierno, como lo entiende Marty Linsky quien dice que:

... las elecciones y el gobierno son juegos de pelota distintos, que se juegan con objetivos y reglas distintos... El fin de las elecciones es ganar, observa correctamente Linsky, expresando el cinismo de los sofisticados. Y 'el fin de gobernar es hacer lo mejor para el país', añade, repitiendo como un loro las necesarias ilusiones que exige la respetabilidad (Linsky citado en Chomsky, 2009: 364-365).

Esto no debe perder de vista que el interés del artículo es la exposición discursiva de los candidatos durante los debates, pero ayuda a posicionar una reflexión importante, que sería donde está participando la ciudadanía en las mentes de los candidatos y como se puede canalizar dichas especulaciones en la construcción de un imaginario discursivo en campaña.

13 La idea del "arrepentimiento" puede ser: arrepentimiento no solo de ser de Liberación Nacional, puede ser un arrepentimiento por ser de partido tradicional y relacionado con la depresión del Estado. Sin embargo, también hay que advertir que el concepto de arrepentimiento es usado aquí como analítico en un sentido más coyuntural que estructural, lo que deja este segundo análisis abierto para afianzar o desestimar el concepto desde el punto de vista politológico, sociológico e histórico.

14 Un estudio de entornos latinoamericanos de izquierda o pseudo-izquierdas en: Figueroa, 2010.
ANÁLISIS DE LOS DISCURSOS EN EL DESARROLLO DE LOS DEBATES EN CAMPAÑA

\section{EL DEBATE BAJO ASEDIO}

Este acápite no está diseñado para ser extenso, sino más bien está pensado para exponer que en primer lugar, la posibilidad de debatir está encerrada en dos horizontes o mejor dicho en dos albas: por un lado, lo desigual en la exposición público-mediática costarricense y global. Por otro lado, el ausentarse de los debates es parte de una estrategia en la que se busca ubicar el contexto enunciativo en la parte más publicitaria de la campaña, la cual es sumamente explícita. Así, la dinámica alrededor de debatir está asediada desde estos dos frentes: desde la estructura mediática de control público-privado de la información y acceso a la difusión, que redunda en no dejar acceder a unos al escenario del debate y por otro, desde los partidos políticos que podrían dirigir sus esfuerzos a la publicidad-comercial, dejando en segundo plano, o intentar eliminar el espacio del debate como dinámica de la formación de juicio político.

A. NO DEJAR O AMPLIAR EL DEBATE. Los que recienten la repulsión de los medios de comunicación nacionales son principalmente los partidos nuevos (o "pequeños"). Resulta importante recordar como las personalidades de trayectoria política aún, siendo participes del contexto electoral, son a su vez relegados a una campaña local, es decir, la desigualdad se basa en que los medios presentan a los partidos tradicionales, negándole acceso a las nuevas posibilidades. Esto resulta en una situación de "premiar" al ya premiado, mientras los nuevos esfuerzos siguen pagando un precio de novatos. Sin embargo, esta idea tiene que matizarse con los criterios de los compromisos ideológicos de esos grupos, las figuras de los grupos, entre otros. En otras palabras, los medios de comunicación parten de lo que se podría llamar la virtualidad del ganador, dan por descontado la campaña abierta y se basan en la tendencia de voto, lo que a su vez redunda en dicha tendencia al estimular en el espectador/público una resonancia sobre los mismos, mientras realiza 
una invisibilización o disonancia sobre los restantes. Esto tiene varias explicaciones y la más fuerte es la capacidad de pautar publicidad en los mismos medios de comunicación, lo cual es parte de la discusión sobre la deuda política, tema que también fue en buena medida discutida en diferentes momentos.

Además, los mismos candidatos desplazados de la posibilidad de mención mediática hicieron llamados críticos a esta situación, inclusive negándose en coordinación ("saboteando") un mismo proceso de debate (véase cuadro 3 . Debate cancelado en la UCR del 21/01/14). Esto da una idea tanto del factor de importancia que los candidatos le dan a este espacio, como la importancia que tiene como legitimador de la dinámica política.

B. ESQUIVAR Y EVADIR EL DEBATIR. Esta reflexión se hace concentrándose en un candidato: Johnny Araya, del Partido Liberación Nacional —el partido activo más viejo-, ya que este no se presentó en varios debates. Esto hace pensar que no fue una situación puntual de una circunstancia, sino de un acto reiterado en un contexto donde los debates se suponen son la carta de presentación de la dimensión generalizada de las elecciones ${ }^{15}$. Paradigmáticamente, se podría señalar el caso donde el candidato no asistió al debate específico en materia de corrupción (ver cuadro 3/debate del 08/01/14) y donde él y su partido cargan con la connotación de corrupción más fuerte. Esto vuelve la atención sobre el tema del poder y las formas de ejercerse $y$ que:

En la actualidad, los principios estratégicos favoritos de los que tienen el poder son el escape, la evasión y la retirada, $y$ su estado ideal es la invisibilidad. Los intentos de prever sus movimientos y las imprevistas consecuencias de sus movimientos (por no hablar de los esfuerzos

15 Si bien es cierto, se han tomado debates dentro del período oficial iniciado el 2 de octubre del 2013, ya desde antes se habían dado otros debates dentro del perfil político y a los que el candidato había faltado en algunas oportunidades, a lo cual él hizo referencia a dicha situación señalando que estaba atendiendo otras prioridades. Véase: Sancho, 2013. por evitar o frenar los más indeseables de ellos) tienen tanta efectividad como una liga para prevenir los cambios climáticos (Bauman, 2000: 46. Cursivas del autor).

En este sentido, no funcionó, según lo que se esperaba que dicha estrategia creara ${ }^{16}$, lo cual era canalizar la transmisión de la propuesta del pun desde los canales del poder y no exponerlo, sino ejercerlo. Esta práctica ya se había implementado durante la campaña del 2006, en la segunda candidatura de Oscar Arias Sánchez:

Puesto que Óscar Arias y el Partido Liberación consideraban que la contienda estaba dirimida de antemano, rehuyendo cualquier confrontación con los otros candidatos, especialmente con Ottón Solís, del PAC, por considerarlo innecesario. Las confrontaciones, desde su óptica, solamente podrían favorecer a aquel $y$ por tanto no estaban en disposición de permitirlo. En las semanas previas a las elecciones, Arias desapareció prácticamente de cualquier tipo de comparecencia con otros candidatos (Rojas, 2009; 19).

Así, la apuesta del pln fue en otro lindero de la campaña, la publicidad. Este espacio se usa $y$ se espera funcione como medio idóneo de transmisión masiva y homogenización de los mensajes, temática que ya los partidos tradicionales han venido haciendo y que tienen presencia sostenida como anteriormente se señaló:

Pero más grave todavía ha sido el hecho de que la inexperiencia de nuestros partidos políticos en temas de publicidad y de marketing electoral los haya conducido a una sobreutilización de los recursos publicitarios más allá de cualquier análisis de rentabilidad, lo cual está en buena medida en el origen de las

16 Se parte de la idea de que no debatir o evadir los debates eran un mecanismo estratégico para no evidenciar aún más el desprestigio del partido y el candidato, buscando salidas mediáticas y controladas. 
prácticas de financiación irregular que se han prodigado entre nosotros durante los últimos años, contribuyendo a generar un clima de corrupción generalizada que ha terminado por afectar a la propia credibilidad del sistema democrático en su conjunto (Caro, 1994: 81-82. Cursivas del autor).

Así, el no debatir, bajo esta última idea de apostar por la sobre-publicidad, tiene un costo tanto en el desempeño político del país, como en la misma credibilidad del partido y candidato, que como se observará en la siguiente sección, ocurrió dentro del contexto del desempeño de los debates analizados.

\section{¿CÓMO SE DEBATIÓ? ESTRATEGIA Y LEGITIMIDAD}

Especulativamente, la importancia de los debates se puede centrar en las elecciones del 2014, con una relevancia muy superior a elecciones pasadas. Partiendo de este punto y en relación con la argumentación teórica, se debe hacer énfasis en la capacidad expositiva de los candidatos, que por un lado, se manifiesta tanto en una teatralidad, como también en una capacidad de organizar el escenario de apoyo, simbólicamente desarrollado. El principal elemento técnico que tienen los candidatos en los debates son las palabras o mejor dicho, la expresividad oral: la retórica. En otros momentos, las imágenes y el sonido (la parte más publicitaria de la campaña) están condicionadas a su vez, por la calidad de la presencia de los candidatos. Así, para estas elecciones, la capacidad de retórica defensiva - los y las ciudadanas - estaba mucho más presente que en muchas otras oportunidades, situación que se derivaría de una pesadumbre social respecto a la valoración deficiente sobre la política y los actores oficiales del Estado y los partidos políticos.

En relación con la metodología, y con el fin de resaltar dicho desempeño, se optó por rescatar marcadores (palabras/símbolos) recurrentes por los candidatos, tanto para atacar, defenderse o visualizarse en el contexto. En el cuadro 4 se presenta la exposición de lo planteado en la metodología preparada (cuadro 1/
Punto B.2.). En esta línea, la idea de combinar programas de gobierno con capacidad creativa de los candidatos se articula en rescatar tres dimensiones: a) un contexto de acusación; b) un escenario de alianzas posibles; $y$ c) los recursos personales a los que se busca acudir y referenciarse como individuo - un ethos explícito. Cada dimensión, relacionadas entre sí, busca mostrar por un lado, los elementos recurrentes, así como la capacidad de integrarlos y usarlos en un desarrollo expresivo. El cuadro 4 busca sintetizar una serie de condicionantes de la construcción de los discursos ${ }^{17}$, en los cuales se utilizan tanto como recordatorios del contexto general (acusaciones), así como, condicionantes de los actores en el espectro ideológico (alianzas). Asimismo, estos repercuten y buscan maximizar el uso de los recursos que el candidato - sea él o asesorado- exhibe en los debates.

Es importante señalar que no se investiga a fondo todos los elementos, ni una amplia gama de comparaciones $y$ reflexiones. Se escogió realizar un proceso de clasificación y proceder a un análisis de los dos primeros candidatos en el orden de votación y de acceso a la segunda ronda. Se espera que la lectora y el lector busquen utilizar, criticar y mejorar este cuadro con sus propios elementos teóricos y metodológicos. A su vez, es importante concentrar la atención en la idea de que se puede leer y analizar el cuadro en la lógica integral de cada discurso por candidato/partido, así como en las columnas, buscando entresacar el valor heurístico del fenómeno de los debates, bajo una lectura, tanto dialéctica como simbólica.

17 Aquí no se usa el término discurso desde su capacidad teórico-metodológica; sino que se apela a su versión del inglés de speech, que hace alusión al acto de enunciar un comunicado-mensaje, con cierta brevedad $y$ con un sentido apelativo a la audiencia. El concepto discourse se reserva al uso analítico profundo, donde además de contener las modalidades de speech, hace énfasis a una dimensión del poder, la estructuración social y política de enunciación, entre otros. Véase sobre esta última forma teórica: Fairclough y Wodak, 2000. 


\section{CUADRO 4 \\ USOS ESTRATÉGICO-RETÓRICOS DURANTE LA PARTICIPACIÓN EN LOS DEBATES 2013-2014}

\begin{tabular}{ll}
\hline CANDIDATO & ACUSACIONES \\
\hline PARTIDO & El candidato del PAC no \\
ACCIÓN & manejó ninguna acusación \\
CIUDADANA & en su contra, ni tampoco \\
(PAC) & ninguna significativa para \\
& con el resto de sus miem- \\
LUIS G. SOLIS & bros de campaña, lo que \\
& le permitió generar acu- \\
& saciones hacia los otros y \\
& manejarse desde la "incues- \\
& tionabilidad", de ser prime- \\
& rizo como candidato presi- \\
& dencial. Tal vez la posible \\
& cuota de "culpa" sería ser el \\
& antiguo secretario general \\
& del pln.
\end{tabular}

ALIANZAS

JOHNNY ARAYA

LIBERACIÓN NACIONAL (PLN) tionado en términos de corrupción y de aprensión del poder político histórico. Atacado por la pluralidad del resto de candidatos. Además, el mismo candidato es cuestionado por su trayectoria de más de 20 años en el mismo cargo público.

\begin{tabular}{l}
\hline PARTIDO \\
FRENTE AMPLIO \\
(FA)
\end{tabular}

No existían acusaciones contra José M. Villalta o su Partido Frente Amplio, lo cual era un elemento

JOSÉ M. VILLALTA de cierta legitimidad que influyó en su desempeño. Además, en lugar de acusaciones en su contra, fue más bien un partido $y$ un político que se ha caracterizado por tener una posición de denuncia, mucho más que los restantes partidos.
PAC-FA: Luis G. Solís no hizo manifestaciones explícitas de buscar alianzas, aunque bajo ciertas presiones marco una relación "ambigua" con el Frente Amplio, que pareciera eran el dúo de trabajo conciente e inconciente dentro de los debates.

El candidato del PLN no realizó o no pudo hacer alianzas, ya que fue el blanco principal: tanto por ser partido histórico y por decirse estar a la cabeza de las encuestas.

RECURSOS PERSONALIZADOS

El principal recurso auto generado (y explotado en toda la campaña del PAC) en su despliegue es el uso de la ecuanimidad e inteligencia en los datos y argumentos. Esto debido a que su condición de profesor universitario e historiador/ politólogo fue mostrada bajo la presentación de una ecuanimidad y parsimonia, que lo distanció de la disputa entre los restantes tres candidatos igualmente mediáticos: Araya, Villalta y Guevara, auto reflejando una virtud de "centrista" claro. Fue expuesto poco por los demás candidatos, lo que le permitió mayor desenvolvimiento en los debates en alguna medida, a diferencia de los siguientes tres candidatos.

El candidato uso tres elementos poco novedosos: su sinceridad autoproclamada y reiterativa. Su experiencia en la función pública, que a su vez era la principal crítica desde los otros candidatos (22 años como Alcalde de San José). Se dijo ser un candidato de unidad nacional, pero en los debates fue el más atacado junto con Villalta. No logró mostrar capacidad para unificar a ninguno de los otros candidatos.

FA-PAC: Motivada desde Villalta. Los tres principales elementos de Medianamente recibida por Solís, la razón es una afinidad en propuestas de programa $y$ aspectos ideológicos $y$ previendo una segunda ronda, principalmente.

debate que uso Villalta fueron: primero el elemento de cuestionar lo mismo de siempre. Si bien como estribillo pudo haber perdido fuerza en cierto punto, logró posicionar la idea de necesidad de cambio. Un segundo elemento fue el tema de la reactivación del Estado en el tema productivo. Por último el ser parte del pueblo, como defensor y creyente en las agrupaciones sociales. 


\begin{tabular}{|c|c|}
\hline CANDIDATO & ACUSACIONES \\
\hline $\begin{array}{l}\text { PARTIDO } \\
\text { MOVIMIENTO } \\
\text { LIBERTARIO } \\
\text { (ML) } \\
\text { OTTO GUEVARA }\end{array}$ & $\begin{array}{l}\text { El segundo partido (inclu- } \\
\text { yendo al candidato) más } \\
\text { cuestionado fue el ML. El } \\
\text { partido y el candidato Otto } \\
\text { Guevara fueron cuestiona- } \\
\text { dos principalmente por el } \\
\text { PLN y el Fa. Se hicieron alu- } \\
\text { siones directas a su com- } \\
\text { portamiento en los rubros } \\
\text { de materia económica libe- } \\
\text { ral y por sus "ambigüeda- } \\
\text { des" en materia de la deuda } \\
\text { política. }\end{array}$ \\
\hline
\end{tabular}

\begin{tabular}{l}
\hline PARTIDO \\
UNIDAD SOCIAL \\
CRISTIANA \\
(PUSC)
\end{tabular}

RODOLFO PIZA

Las acusaciones contra

el partido son fuertes $y$ con procesos judiciales para dos expresidentes, en las últimas dos décadas. Si bien, el candidato no presenta cuestionamientos legales, ni otros públicos, si carga con una condición de partido desacreditado, tanto por dichos expresidentes, como también por una inconsistencia en lo que sería el candidato para esta elección antes que Rodolfo Piza, quien claudicó dos veces en menos de un mes, Rodolfo Hernández.

\begin{tabular}{ll}
\hline PARTIDO PATRIA & Los cuestionamientos \\
NUEVA & sobre José M. Corrales no \\
(PN) & se presentaron, aunque se \\
& recordó que fue miembro \\
JOSÉ M. & del Partido Liberación \\
CORRALES & Nacional, pero del cual, él \\
& mismo posicionó la idea \\
& de desvincularse por ser \\
& un partido "corrompido". \\
& El partido que representa, \\
& Patria Nueva, al ser nuevo, \\
& no presentaba mayores \\
& antecedentes en varios \\
& sentidos.
\end{tabular}

ALIANZAS

ML-Pusc: Guevara intentó generar el vínculo, Piza lo eludió directamente. Razón: Se estima que Guevara trataba de captar votos de un débil pusc.

PUSC-ML: Esta alianza que Piza no alentaba. No era tan querida, debido a que restaba fuerza a un partido ya de por sí golpeado. Era una alianza contra-producente.

PN: no generó directas alianzas con los restantes partidos de mayor voto. Su posición fue de vínculos generales. Sin embargo, por su perspectiva de programa se podría vincular con los partidos PaC y FA.
RECURSOS PERSONALIZADOS

El candidato Guevara realizó uno de los despliegues de teatralidad más fuertes de todos los candidatos. Lo que pareciera fue tan sobre-actuado, que la teatralidad fue exagerada. Además mostró disposición de multi-vinculación, es decir, mostró interés de vincularse con diferentes espacios sociales, no importando si eran contrarios. También optó por tomar posiciones más conservadoras hacia el final de los debates.

Parte de lo que R. Piza usó durante los debates fue una apelación a la idea de lo serio (y lo uso a lo largo de toda su campaña). Llevó esto al grado tal de una postura de regaño, tanto para la audiencia, pero en especial con los demás candidatos. Uso su experiencia como lema de eficiencia y la seriedad como fundamento básico de lo político y la gestión pública. Los debates fueron usados como punto para presentarse con una sobre-dimensión de seriedad.

\begin{abstract}
Los tres principales elementos del discurso que utilizó fueron: en primer lugar, la experiencia en la gestión pública; segundo, la posición de estar dentro de un proyecto con una connotación de patria, que hace alusión a un patriotismo esencial en él, un verdadero patriota; por último, una forma coloquial de expresión que combina tanto una modalidad anecdótica - que también amalgama la idea ya asociada con él de honestidad-, con una crítica a los proyectos políticos actuales desde una connotación "democrática renovada".
\end{abstract}

Fuente: Elaboración propia a partir de lo expresado por los candidatos en los debates en análisis, 2013-2014. 
Como se indicó en el cuadro 4, se recoge más información de la que es posible analizar en este artículo; sin embargo, es importante resaltar tres reflexiones puntuales correspondientes a cada una de las dimensiones:

1) Acusaciones: respecto a este punto, tres partidos condensan el peso socio-político, el PLN, el ML y el PUSC. Los demás partidos se les ha cargado con mucho menor peso o ningún cargo, respecto a rubros legales o de acusaciones. Este elemento en el juego constructivo de los discursos de los candidatos, es uno que se podría situar como fundante de casi todas las campañas y que puede ubicar a un grupo, o inclusive sobre el Partido Liberación Nacional como el ofensor socio-político en materia de corrupción. La sobreexposición del PLN y su candidato Johnny Araya fueron una factura que se pagó antes de la "contratación", que el candidato intentó presentar como elemento simbólico de sus capacidades. Hasta pocos días antes de terminar la campaña se expusieron cuestionamientos de corrupción de su gestión en la municipalidad, así como también de su supuesto distanciamiento del gobierno actual ${ }^{18}$.

2) Alianzas: las alianzas fueron estrategias forzosas; es decir, fueron intentos de posicionar a un candidato/partido distinto como un posible apoyo. Sin embargo, una vez que algún partido hacía este llamado/solicitud, el candidato receptor de la petición, presentaba un bloqueo o una serie de esquivas al compromiso. Es importante resaltar que el PLN nunca fue llamado para formar ninguna alianza por estos otros 5 candidatos ( $y$ del total de los 13 candidatos, los más cercanos fueron los dos candidatos de partidos cristianos:

$18 \quad$ Para un ejemplo véase la información publicada por el Semanario Universidad, donde evidencia la cercanía del candidato Johnny Araya (ex alcalde de la Municipalidad de San José) con un importante empresario en construcción (Carlos CerdasConstructora MECo), quien tiene varias licitaciones con la municipalidad y los últimos gobiernos de Liberación Nacional (Rivera, 2014).
Partido Restauración Nacional (PRN) y Partido Renovación Costarricense (Rc)), esto irónicamente siendo Johnny Araya el que mantenía el estandarte de la unidad nacional.

3) Recursos personalizados: la teatralidad fue $y$ es la herramienta clave de la construcción discursiva. Sin embargo, no resulta efectiva sin símbolos por desarrollar y un contexto de enunciación con los cuales crear y jugar. Los recursos con los que se ejerció la teatralidad estuvieron asociados principalmente con aquello que distanciara de la corrupción, por lo cual, el PLN y el ML $^{19}$ y sus candidatos, sean o no corruptos, se vincularon simbólicamente con dicha connotación, lo cual los recursos de trayectoria limpia $y$ de novedad, fueron mucho mejor desarrollados y usados en contexto, aprovechando un entorno hostil hacia la visión de continuidad y de abusos "generalizados". Fueron el pac y el Fa quienes mejor lo canalizaron.

\section{CONCLUSIONES: EL DEBATIR COMO UNA POLÉMICA SHAKESPEARIANA}

Pudiendo extraer varias conclusiones del documento, se optó por evidenciar tres significativas lógicas explicativas de la dinámica de los debates, pero dentro del contexto socio-político existente. Esto se despliega

19 Tanto fue esto que en los resultados finales para la primera ronda del $\mathrm{ML}$, tanto para presidente como para diputados, recibieron resultados mucho más bajos que los que las mismas encuestas previas habían señalado. Otto Guevara en su candidatura (4 candidaturas consecutivas) para presidente quedó de cuarto lugar (11,3\%), y en términos de diputados perdieron 5 curules respecto a las 9 que tuvieron en el período 2010-2014. Desde el punto de vista del desempeño político-histórico: "Guevara presenta un nivel de rechazo que aumenta gradualmente con el tiempo para llegar a su máximo en enero del 2006" (Rodríguez, 2013: 92). Aclarando que en dicho período legislativo, varios diputados se separaron de la fracción. Además, resulta que el partido atacado por Araya y Guevara de izquierdista y comunista (el Frente Amplio), obtiene 9 diputaciones, la mitad de las 18 curules que logró Liberación Nacional, cifra más baja registrada para el partido tradicional. 
dando respuesta a la pregunta sobre el papel del peso discursivo evidenciado durante los debates. Dicho contexto se resume a su vez en otras tres trayectorias fundamentales: 1) la desgastada trayectoria política del Partido Liberación Nacional; 2) la lógica de la cultura política costarricense sobre el paradigma de la neutralidad política; 3) El aparente giro latinoamericano hacia la izquierda, a partir de una deslegitimada derecha histórica. A su vez hay que rescatar analíticamente, que cada uno de estos tres criterios contextuales remite a una variable epistemológica importante. En el caso de la trayectoria histórica desgastada del PLN (1), el fundamento es tanto coyuntural como estructural. Por un lado, el peso negativo en una imagen pública del gobierno y partido en que el gobierno de Laura Chinchilla (2010-2014) se posicionó de una manera particularmente mala, frente a otros gobiernos. Por otro, la corrupción manifiesta en las denuncias y desde la opinión pública sostenida, dan cuenta de la forma en que se opera desde un partido que existe para mantenerse gobernando, lo que señala una estructura. El punto cultural (2) evidencia una forma de razonar o "sentimentalizar" el voto, donde el criterio de acción política neutral tiene también un peso en valorar la manifestación en diferentes modalidades pública, "extrema", no oficial, etc. como una afrenta al cuerpo social (pacífico míticamente), más que al Estado como tal. Por último, el fenómeno latinoamericano de un giro de izquierda, sean izquierdas de fondo o algo de fondo, o pseudos-izquier$\mathrm{das}^{20}$, propicia un paradigma de cambio ${ }^{21}(3)$.

Dentro de este contexto general, se señala las ideas que se pueden entrever combinando el desempeño en los debates y los resultados de la contienda política en las dos rondas electorales. Como se indicó, las conclusiones clave son tres y cada una se señala bajo un título articulador:

$\overline{20}$ Para ver una reflexión del giro hacia la izquierda y/o un aparente giro hacia la izquierda en América Latina, véase: Figueroa, 2011 y Zibechi, 2014.

21 Los puntos 2 y 3 chocan entre sí, lo cual deja un importante espacio de reflexión a cubrir en otros documentos, pero que permite ver la dialéctica entre estructura cultural y estrategias políticas.
A) POR MEDIA CALLE. La dinámica del espectro electoral versó en mucha medida por ser/aparentar la centralidad del espectro. 13 partidos y 13 candidatos, en donde muy pocos se ubicaban más allá de una ambigua centralidad. Casi todos señalaban ser en alguna medida, centrales. Señalaban ser de centro, pero con tendencias: izquierda, derecha, inclusive se podría señalar el ser de "centro-centro", haciendo alusión a la pureza esencial de ser el "verdadero" centro. Este elemento va más allá de los debates y fue puesto como núcleo en la mayoría de los discursos de campaña de los partidos/candidatos. Dentro de una gama de 13 partidos, pareciera que el tener la posición de centro garantiza la mayor posibilidad de ganar elecciones. Se hace la alusión de que ser de centro es igual a equilibrio y armonía, e inclusive, se puede ser de alguna extrema, pero el término centro tiene que ubicarse en algún lado, como adjetivo o como apellido, con tal de darle un matiz armonizador (dentro de la culturalidad política costarricense) a los programas y partidos en contienda electoral. Parece que de manera singular, los costarricenses somos más aristotélicos que otra cosa. Asimismo, en un sentido mucho más mundano que la metafísica aristotélica, se recuerda que el ser humano "aunque es capaz de trascendencia, el hombre sabe que su lugar no está en los extremos. Puede conducir su vida en el equilibrio, una vida de hombre, fiel a su destino de justo medio" (Hersch, 2010: 66). La idea clara es señalar que la disputa por este criterio, por este adjetivo fue fuertemente elaborado $y$ en buena medida, el PAc $y$ en especial su candidato, lograron captar y restárselo a los otros, en especial al partido que se ha señalado como el centro puro, el pLN. La exposición de criterio de inteligencia, ecuanimidad y parsimonia por parte de Luis G. Solís, eventualmente lograron calar más como indicadores de centro, que las referencias de auto-sinceridad y experiencia del liberacionista Johnny Araya, menos tampoco su aclamación por la unidad nacional surtió efecto como aglutinador. Se resalta que el candidato Solís y el Partido Acción Ciudadana registraron datos bajos en las encuestas ${ }^{22}$ al inicio de la

22 Véase la encuesta de UNIMER (diciembre, 2013): Johnny Araya decayó de $42 \%$ a $38 \%$ del apoyo, 
campaña en comparación con los demás candidatos que quedaron entre los primeros cuatro. $\mathrm{Su}$ gane podría justificarse parcialmente dentro de la propuesta de este artículo, donde se indica que la dinámica del debate logró posicionar la lucha y potenciar la capacidad y la retórica de la misma, bajo los espectros simbólicos señalados, como lo fue la idea de "colonizar" el centro. Pero es un perfil de análisis que debe conjugarse con otros elementos como estructura de base para alcanzar una capacidad heurística de análisis y de pesos entre dimensiones.

Las ideas anteriores tienen que leerse en contexto, rescatando dos elementos. Una lógica de repudio contra el $\operatorname{PLN}^{23} y$ que redunda a su vez en el segundo elemento, el de continuismo del mismo Partido Liberación. En otras palabras, el peso de los debates, no se da en un vacio de sentido; está ramificado con su contexto de enunciación que es histórico y cultural. La legitimidad en el "centro" no fue lo que se dañó, sino en quién ocupa el puesto ${ }^{24}$. Asimismo,

mientras que L.G. Solís se mantenía entre 3\% a $8 \%$ del apoyo, a dos meses de las elecciones del 2 de febrero (Oviedo, 2013). Fue precisamente en ese lapso donde los debates se intensificaron. Una revisión y análisis sobre las encuestas queda para otro momento y es fundamental hacerla.

Florisabel Rodríguez (2013) detecta este comportamiento, aunque no le da el matiz de repudio, sino se posiciona en una vertiente que se podría llamar resumidamente des-alineamiento (concepto que tiende al ideario de la ciencia política y de pertenencia partidista), lo que muestra otra forma ideológica y teórica de aproximarse al problema de la deslegitimación del PLN en Costa Rica. En este caso, repudio hace constar más el ámbito de elementos valorizados como vergüenza, odio $u$ otros que están jugando en el ideario simbólico nacional desde hace tiempo en relación con la política.

La idea del centro y de su legitimidad en Costa Rica se trató en Rodríguez (2013); sin embargo, no se profundizó. El trabajo editado por Florisabel Rodríguez se concentró en señalar el manejo del PLN de dicho centro, principalmente en el caso de la campaña de elección en la que participó Laura Chinchilla y como una causa del gane de Chinchilla. En el presente artículo se postula que en la última campaña fue un factor de peso, pero esta vez en contra del mismo Liberación Nacional. Además, es importante hacer una crítica (entre varias posibles, pero no es el momento) al trabajo de Rodríguez (2013) en donde entre las razones pareciera que los símbolos y señales de cambio, sin abandonar la tibieza del centro, fueron expuestos mejor $y$ adrede por el Pac en la presencia teatral y discursiva de su candidato; siendo el partido y su candidato también ex-liberacionistas, un: ¿"nuevo centro" tal vez?

B) ME ARREPIENTO DE LOS PECADOS: otro elemento fundamental de señalar es que, así como J. Baudrillard detectó/denominó a los exizquierda con un arrepentimiento, en el caso de los todavía pertenecientes o a los retirados miembros o identificados con el pLn, se detecta a su vez un arrepentimiento por ser del partido Liberación, es decir, la forma de re-construcción de lo que hoy se denomina el pLs tiene una connotación tan fuertemente marcada por la corrupción y el abuso, que se ha convertido en un elemento simbólico peyorativo como fuerza política. Lo que en buena medida era un símbolo de "desarrollo" y "prosperidad" del país, como un momento de re-nacimiento de Costa Rica en la "Segunda República", política e ideológicamente fundada bajo la idea de un padre fundador - José Figueres Ferrer-y un partido político fundador - Liberación Nacional-, ese símbolo ahora se presenta bajo dos posibles connotaciones críticas. La primera, que caducó el modelo operativo del partido o segunda, personas con "ideales" y valores distintos a los esenciales del partido lo han contravenido. Sea cual sea, la posición sobre las razones del derretimiento de la solidaridad política hacia el partido, el candidato Araya tuvo que lidiar con dicho contexto simbólico. Dentro del la dinámica del debate ese punto fue reiteradamente usado $y$ el candidato no pudo, o no tenía los elementos racionales o pasionales suficientes para revertir ese sentir social del entorno. Además, las capacidades retóricas, así como, los elementos usados (cuadro 4) no ayudaron a revertir o posicionar otros temas de discusión. Se está ante

que da para el gane del PLN en 1994, 2006 y 2010 no menciona, preocupantemente la estructura partidista del Partido Liberación, ni los elementos de teoría política de clientelismo y paternalismo histórico. Aunque haga énfasis en el efecto mediático y de percepción de la opinión, sin esos dos rubros el análisis no profundiza en estructuras y manejo de recursos de diferente naturaleza. 
un entorno adverso principalmente para un partido, en este caso el partido históricamente regular y simbólicamente dependiente de las apelaciones a la continuidad.

El arrepentimiento y la vergüenza se exacerbó: 1) por medio de los debates, donde no podía esquivarse la alusión directa a la incompetencia, corrupción, intransigencia, etc. sobre el partido y el presente gobierno liberacionista. No solamente el vilipendiado gobierno de Oscar Arias $^{25}$ y principalmente, el de Laura Chinchilla desgastó la imagen del partido, sino también que en los debates se logró canalizar de manera simbólica un solo enemigo común, que ya venía estando en evidencia en los últimos años, pero los debates permitieron canalizar en los otros candidatos una forma catártica de "venganza", así también como una forma catártica de reivindicación al arrepentirse $\mathrm{e}^{26}$ y 2) por el comunicado de Johnny Araya del 5 de marzo de no continuar activamente en la campaña electoral para la segunda ronda ${ }^{27}$. Este acto queda fuera del margen de análisis, pero podría ubicarse en esta línea de incrementar un sentimiento de odio $y$ un sentimiento de arrepentimiento-vergüenza. Es ahí en que se une ideológicamente con Luis G. Solís como candidato de los redimidos $y$ redentores ${ }^{28}$.

25 Aunque Rodríguez (2013) indica más bien que el Gobierno de Oscar Arias tenía alta aceptación, según datos de encuestas y metodologías de estudios de opinión. Sin embargo, el argumento es cuestionable.

26 La alusión no es lisonjera. El contexto conservador-religioso de Costa Rica marca una importante tónica hacia el uso de figuras simbólicas cristianas para la forma de interactuar.

Esta decisión puede interpretarse como una rendición o como una estrategia, cualquiera sea el caso, no funcionó en el tema de subsanar la recriminación ya existente. Sin embargo, queda un análisis depurado de este segundo proceso electoral.

Se sugiere retomar la idea de valorar si el PAC es una re-construcción de un Liberación Nacional que está en proceso de desaparición, así como estaba desapareciendo el partido Republicano Nacional de Rafael Calderón Guardia a finales de los 40, solo que en esa oportunidad no mutó en el PLN, sino que el PLN es el resultado y elemento de legitimización del poder después del enfrentamiento del 49. Véase: Molina y Lehoucq, 1999 y
C) ¿DEBATIR O NO DEBATIR?: la reflexión política sobre un aprendizaje desde el Hamlet de William Shakespeare tiene una pluralidad de aproximaciones, más permite leer el escenario político costarricense de una manera, si bien posiblemente maniqueista, a la larga enriquecedoramente cuestionadora. "To be, or not to be" (Ser, o no ser): donde el ser $^{29}$ puede retrotraer al accionar, al actuar, mientras el no-ser aprisiona en la inacción. La metáfora escogida en el título vislumbra al debate como un ser o una dimensión del ser en su condición de acción; la capacidad de construcción retórica y de retórica-defensiva es un acto que los debates, por su naturaleza dialéctica, estimula y fomenta. Por el contrario, la posición de no debatir podría llevar a un estímulo y condición de inacción, $y$ la capacidad de actuar se buscaría neutralizar, a costa de un incremento en la vida política en diferentes dimensiones, entre estas, las de crítica y de re-posiciones respecto a consecuencias y tragedias.

\section{BIBLIOGRAFÍA}

\section{LIBROS}

Aristóteles. Política. España: Biblioteca de Filosofía de Ediciones Mesta, 2004.

Aristóteles. El arte de la retórica. México DF, México: Editorial Porrúa, 2013.

Baudrillard, Jean. La ilusión del fin. La huelga de los acontecimientos. España: Colección Argumentos de Editorial Anagrama, 2004.

Bauman, Zygmunt. Modernidad líquida. México: Fondo de Cultura Económica, 2000.

Bauman, Zygmunt. Vidas desperdiciadas. La modernidad y sus parias. Barcelona, España: Estado y Sociedad de Editorial Paidós, 2005.

Rovira, 2000.

29 Pensar el ser nos volvería sobre reflexiones filosóficas (metafísicas, existencialistas, escépticas) que exceden en demasía los contornos reflexivos de este estudio. Sin embargo, se está anclado en una reflexión de la acción, lo que nos vincularía en la línea existencialista y del accionar político que esta corriente manifiesta. 
Caro, Antonio. La publicidad que vivimos. España: Eresma \& Celeste Ediciones, 1994.

Chilton, Paul y Schäffner, Christina. "Discurso y política". El discurso como interacción social. Estudios sobre el discurso. Una introducción multidisciplinaria. Volumen II. Van Dijk, Teum (compilador). España. Editorial Gedisa, 2000: 297-330.

Chomsky, Noam. El miedo a la democracia. Barcelona, España: Editorial Crítica, 2009.

Del Rey Morató, Javier. La comunicación política (El mito de las Izquierdas y Derechas). Madrid, España: Editorial EUDEMA, 1989.

Dorfles, Gillo. Símbolo, comunicación y consumo. España: Editorial Lumen, 1984.

Fairclough, Norman y Wodak, Ruth. "Análisis crítico del discurso". El discurso como interacción social. Estudios sobre el discurso II. Una introducción multidisciplinaria. T. Van Dijk (Compilador). Barcelona, España. Editorial Gedisa, 2000: 367-404.

Figueroa, Carlos. ¿En el umbral del posneoliberalismo? Izquierda y gobierno en América Latina. Ciudad de Guatemala, Guatemala: Editores F\&G, 2010.

Flórez-Estrada, María y Hernández, Gerardo. TLC con Estados Unidos. Contribuciones para el debate. ¿Debe Costa Rica aprobarlo? Costa Rica: Instituto de Investigaciones Sociales (IIS) de la Universidad de Costa Rica, 2004.

Foucault, Michel. Vigilar y castigar. México DF, México: Siglo xxi Editores SA, 1976.

Govaere, Velia y Ocampo, Fernando (ed.). Ensayos temáticos sobre el TLC. República Dominicana-CentroaméricaEstados Unidos. San José, Costa Rica: Editorial Universidad Estatal a Distancia (UNED), 2005.

Hersch, Jeanne. El gran asombro. La curiosidad como estímulo en la historia de la filosofía. España: Editorial Acantilado, 2010.
Molina, Iván y Lehoucq, Fabrice. Urnas de lo inesperado. Fraude electoral y lucha política en Costa Rica (1901-1948). San José, Costa Rica: Editorial de Costa Rica. Colección Identidad Cultural, 1999.

Rodríguez, Florisabel. Costa Rica: ¿Quién decide? Elecciones, compañas y sociedad 1994.2010. Costa Rica: flacso-Serie Informes de Investigación, 2013

Rovira, Jorge (editor). Desafíos políticos de la Costa Rica actual. Costa Rica: Instituto de Investigaciones Sociales (IIS) Editorial de la Universidad de Costa Rica (UCR), 2007.

Rovira, Jorge. Estado y política económica en Costa Rica. Costa Rica: Instituto de Investigaciones Sociales (IIs) Editorial de la Universidad de Costa Rica (ucR), 2000.

Rojas, Manuel. "Elecciones y referéndum: un balance general". Elecciones de 2006 y Referéndum: perspectivas diversas. $\mathrm{M}$. Rojas y M. Castro (comp.). San José, Costa Rica: flacso, 2009.

\section{PUBLICACIONES PERIÓDICAS}

Guadalupe, Bertha. "Ética y política en Platón". Logos 10 (30). México DF, México. Escuela de Filosofía de la Universidad de La Salle, 1982: 49-74.

Labarriere, Jean-Louis. "Del discurso político como "apariencia engañosa". Teoría política y comunicación. Barcelona, España. Editorial Gedisa. Barcelona, 2001: 9-18.

Rivera, Ernesto. "Araya y presidente de meco volaron en secreto a Panamá". Semanario Universidad. Universidad de Costa Rica. 2 de abril de 2014. En: $<$ http://www.semanariouniversidad. ucr.cr/index.php?option=com_content $\&$ view $=$ article $\& \mathrm{id}=12787 \&$ Itemid $=70>$ [Consultado el 3 de abril de 2014].

Sancho, Manuel. "Johnny Araya asegura que falta a ciertos debates, por tener otras prioridades en agenda". CRhoy. 23 de noviembre de 2013. En <http://www. crhoy.com/johnny-araya-asegura-quefalta-a-ciertos-debates-por-tener-otrasprioridades-en-agenda/> [Consultado el 04 de abril de 2014]. 
Troncoso, Alfredo. "El fundamento filosófico de la retórica en los sofistas". Logos 11 (32). México df, México. Escuela de Filosofía de la Universidad de La Salle, 1983: 91-108.

Oviedo, Esteban. "Encuesta de Unimer: Costa Rica sin favoritos a dos meses de elecciones". La Nación. 1 de diciembre de 2013. Costa Rica. En: <http://www. nacion.com/nacional/Pais-favoritomeses-elecciones_0_1381461963.html> [consultado el 3 de abril de 2014].

TEXTOS ELECTRÓNICOS

Zibechi, Raúl. "Derechas con look de izquierda". América en movimiento. Quito,
Ecuador: Agencia Latinoamericana de Información. 7 marzo de 2014. En: $<$ http://alainet.org/active/71859> [Consultado el 16 de marzo de 2014].

Cambronero, Natasha. "ucr suspende debate de este martes porque cuatro candidatos cancelaron participación". 5 de marzo de 2014. En: <http://www.ameliarueda. com/nota/ucr-suspende-debate-deeste-martes-porque-cuatro-candidatoscancelaron-part> [consultado el 27 de febrero de 2014].

Fecha de ingreso: 21/04/2014 Fecha de aprobación: 17/07/2014 